\title{
Experimental Tests of Local Scour at Circular River Piers with Truncated Cone Foundation
}

\author{
[ G. Ciaravino, C. Ciaravino ]
}

\begin{abstract}
Stream flow in mobile river beds gives rise to scour phenomena around river piers that may jeopardize the stability of the bridge. As scour is dependent on pier shape (among other factors), estimating equations generally introduce shape coefficients. In the present study experimental tests concerning scour phenomena have been carried out on a particular shape of the already effective circular piers in order to determine if any improvement is verified in their shape coefficient (with a corresponding decrease in scour). In particular, the circular pier foundation has been shaped as a truncated cone, partially or totally sunk into the mobile bed. In the experimental tests a preliminary comparison has been effected between scour at uniform circular pier and non uniform piers with two different values of bevel angle for the truncated cone foundation. Experimental results have showed that, for both values, the scour depth has been lower than that identified in experimental tests conducted on circular piers of the same diameter but without the truncated cone foundation.
\end{abstract}

Keywords-scour phenomena, mobile bed, river piers, bridge stability.

\section{Introduction}

The problem of scour around isolated structures in stream flow, such as bridge piers sunk into the river bed, has been widely studied as testified by the international scientific literature concerning this topic. Early studies aimed to determine the field of motion and the mechanical schema of the erosive phenomenon [1-3], others assessed methodologies and relations for estimating scour entity [4-15], while later researches studied the evolution of the erosive phenomenon over time [16-18].

It has been observed that scour is specifically affected by the shape and size of the pier as well as by its position with respect to stream flow $[1,3,4,11]$. In other words, both river bed erosion and hydrodynamic action on the pier are affected by the shape and size of the pier. For purposes of application, in case of scour $\mathrm{Y}_{\mathrm{s}}$ corresponding to an isolated pier, considerable acclaim was paid to the equation suggested by Breusers, Nicollet and Shen [11] which is effectively an envelope equation of the various experimental results:

Giulio Ciaravino

Full Professor, University of Naples Federico II, Italy

Cristiano Ciaravino

Engineer + MEng, Italy

$$
\frac{\mathrm{Y}_{\mathrm{s}}}{\mathrm{b}_{\mathrm{p}}}=\left[2.0 \cdot \tanh \left(\frac{\mathrm{y}}{\mathrm{b}_{\mathrm{p}}}\right)\right] \cdot \mathrm{f}_{1}\left(\frac{\mathrm{V}}{\mathrm{V}_{\mathrm{cs}}}\right) \cdot \mathrm{f}_{2}(\text { shape }) \cdot \mathrm{f}_{3}\left(\alpha, \frac{\mathrm{L}_{\mathrm{p}}}{\mathrm{b}_{\mathrm{p}}}\right)
$$

where $b_{p}$ and $L_{p}$ are pier width and pier length respectively, $y$ is the approach flow depth, $\mathrm{V}$ and $\mathrm{V}_{\mathrm{cs}}$ are the average approach velocity and the critical entrainment velocity and $\alpha$ is the angle relative to approach flow direction. In equation (1) $\mathrm{f}_{1}$, depended to the $\mathrm{V} / \mathrm{V}_{\mathrm{cs}}$ ratio, can be determined from the $\mathrm{V}_{\mathrm{cs}}$ value defined by the equation of Hanco [9]:

$$
V_{c s}=1.2 \cdot \sqrt{g \cdot d_{s} \cdot \frac{\rho_{s}-\rho}{\rho}} \cdot\left(\frac{y}{d_{s}}\right)^{0.2}
$$

where $\rho, \rho_{s}$ and ds are fluid density, sediment density and sediment size, respectively; furthermore $f_{3}$ can be deduced from the well-known nomograph set up by Laursen and Toch [4] as a function of the angle $\alpha$ and the $L_{p} / b_{p}$ ratio; finally $f_{2}$ is a coefficient depended to the pier shape. Hence, the search for pier geometric conformations, which provide favourable values of the $f_{3}$ and $f_{2}$ coefficients, is of considerable importance in the field of pier design. In technical practice, designers frequently opt for the uniform circular pier which not only has a favourable value of shape coefficient but also maintains this value for any variation in stream flow direction. In this study, experimental scour tests have been carried out for a particular shape of the already effective circular piers in order to ascertain any improvement in their shape coefficient (through a decrease in scour).

\section{Pier studied and experimental set-up}

It is well known that the bottom section of a river bridge pier (hereafter called the pier base) is subject to the action of the stream flow and of the sediment transported in the proximity of the river bed and in suspension. Therefore it seems fitting to protect the pier (and any reinforcing elements) from this action on its surface. The abrasive action of transported sediment is a major issue for piers located in rivers subject to torrential flows where the material transported substantially comprises sharp-edged stones. Typically, in order to distribute stresses in the foundation and also to protect the pier base, the pier is configured in one of several more or less massive shapes that leads to considerable scour on the mobile river bed: a schematic example studied in recent works [13, 14] is reported in Fig. 1. 


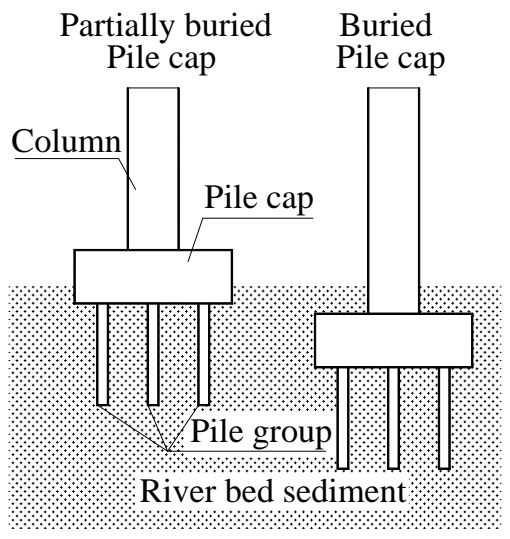

Figure 1. Examples complex piers.

Taking these considerations into account, it was hypothesised that the circular pier could be given a truncated cone shaped foundation partially or totally sunk into the erodable river bed, as showed in Fig. 2. In particular, Fig. 2 shows the geometries tested in the experimental set up corresponding to six cylindrical piers of diameter D varying from $0.08 \mathrm{~m}$ to $0.20 \mathrm{~m}(0.080 ; 0.100 ; 0.125 ; 0.140 ; 0.160$; 0.200 ) with and without a truncated cone base as their foundation. Two truncated cone foundations have been tested, with the bevel angle $\beta$ relative to the vertical axis of the base equal to $30^{\circ}$ and $45^{\circ}$ and a greater diameter respectively equal to $0.20 \mathrm{~m}$ and $0.32 \mathrm{~m}$. (see Fig. 2). It was decided to restrict the value of the $\beta$ angle in order to ensure geometries covering a smaller surface area, which is an important technical consideration. As the circular pier with a diameter of $0.20 \mathrm{~m}$ almost entirely covers the truncated cone base with angle $\beta=30^{\circ}$, a total of seventeen geometries have been tested (six piers without the truncated cone base, six piers with a truncated cone base with angle $\beta=45^{\circ}$ and five piers with a truncated cone with angle $\beta=30^{\circ}$ ) which enabled an initial comparison of the behaviour of the uniform circular (cylindrical) pier (whose foundation is hypothesized at a level deeper than the expected scour) and that of the shaped pier with the truncated cone base. The set-up for the experimental tests was housed in a variable slope channel (maximum obtainable slope $18^{\circ}$ ) measuring $27.26 \mathrm{~m}$ in length with a closed circuit supply currently in use in the Experimental Laboratory at the Department of Civil, Environmental and Architectural Engineering of the Federico II University of Naples.

In particular, the experimental set-up comprises:

- an initial ascending section measuring $3.00 \mathrm{~m}$ in length;

- a section $2.40 \mathrm{~m}$ in length reproducing a mobile river bed (in which the piers being tested have been sunk). The bed erodible material is made up of variable grain-size sand passed through a series of sieves which make it possible to
Piers with diameter D from 0.08 to $0.20 \mathrm{~m}$

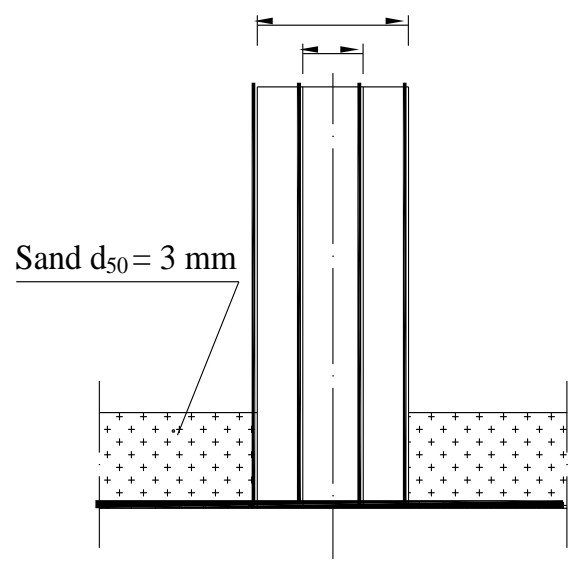

Piers with diameter D from 0.08 to $0.16 \mathrm{~m}$

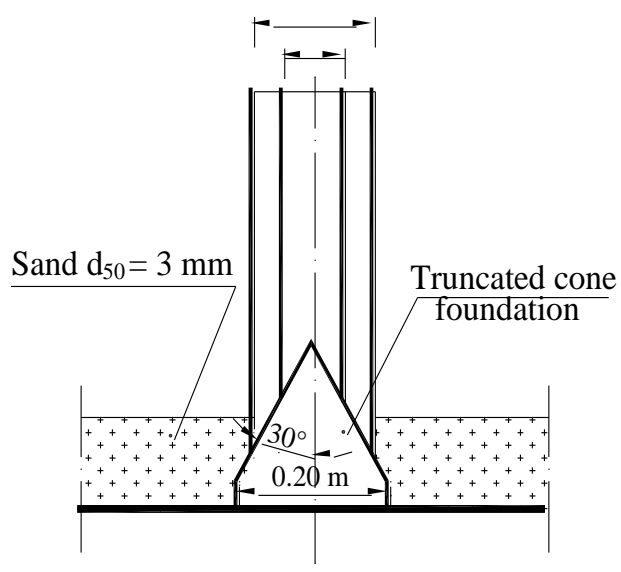

Piers with diameter D from 0.08 to $0.20 \mathrm{~m}$

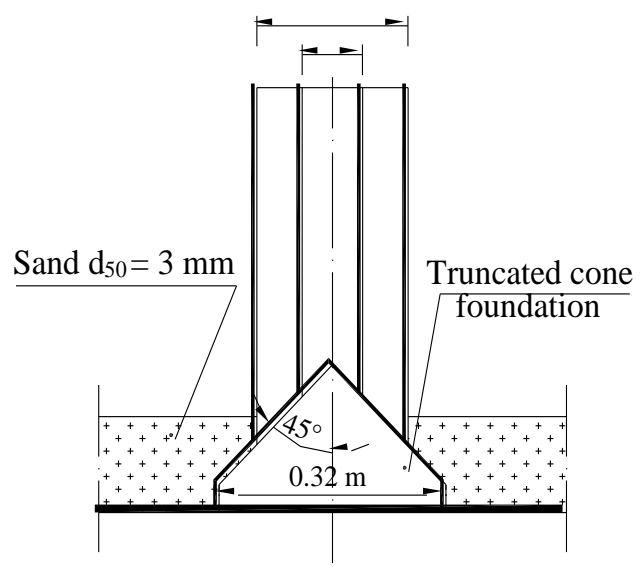

Figure 2. Layouts of circular piers with or without truncated cone foundation used in the tests. 
reconstruct the granulometric curve that gives a median sediment size $\mathrm{d}_{50}$ of $0.003 \mathrm{~m}$;

- a return slide measuring $2.10 \mathrm{~m}$ in length;

- a device for trapping the material transported by the stream, which comprises a grill of suitable mesh to ensure that this material does not end up in the recycle circuit;

- a weir for measurement and control positioned at the end of the channel (which also completes the work of the entrapment device).

In the tests carried out, the slope of the mobile river bed has been made equal to $1 \%$, while the test flow $\mathrm{Q}$, equal to $0.0118 \mathrm{~m}^{3} / \mathrm{s}$, has been determined (by a series of preliminary tests) as the flow rate that, with the assigned slope, determines conditions close to that of incipient motion of the sediment reproducing the mobile river bed (in clearwater conditions). The flow rate is measured by two devices (one of which is electromagnetic) sending their readings to a control desk which also regulates the slope of the channel.

In such experimental conditions low values of water depths and scour depths have been obtained; as a consequence the preliminary tests have pointed out that, already with a test duration of $1.5 \mathrm{~h}$, the solid transport with consequent increase of erodible material found in the trapping device can be considered negligible. This finding is consistent with the well known circumstance that the time needed to develop equilibrium depths of scour at bridge piers is approximately proportional to the volume of the equilibrium scour hole for a given flow condition $[19,20]$.

\section{Experimental tests}

Tests have been carried out for the described geometries (see Fig. 2) and the scour measurements taken at the end of the tests have been collected and expressed in graphs and tables (not reported here for brevity's sake).

In particular, the tables report the scour values for the horseshoe-vortex and the scour measurements taken downstream of the piers corresponding to the wake-vortex.

The tests showed that scour in the area immediately surrounding the pier has the typical "horseshoe" shape whose front width (at bed level) $\mathrm{W}_{\mathrm{s}}$, corresponding to an arc of $180^{\circ}$, has been almost constant in size; in particular, it has been noticed that:

- in case of piers with a truncated cone foundation, $\mathrm{W}_{\mathrm{s}}$ appears to depend substantially on the angle assigned to the truncated cone foundation and is, therefore, practically constant as the pier diameter $\mathrm{D}$ varies for each of the two foundations tested (in fact the tests show that the foundation with $\beta=30^{\circ}$ has $\mathrm{W}_{\mathrm{s}}$ values that are on average about $25 \%$ smaller);

- where no truncated cone foundation is present, $\mathrm{W}_{\mathrm{s}}$ is variable and increases with the pier diameter D (with values substantially ranging between the values measured for the foundation with $\beta=30^{\circ}$ and the values measured for the foundation with $\beta=45^{\circ}$ ).
The above-described characteristics can also be deduced from the graph in Fig. 3.

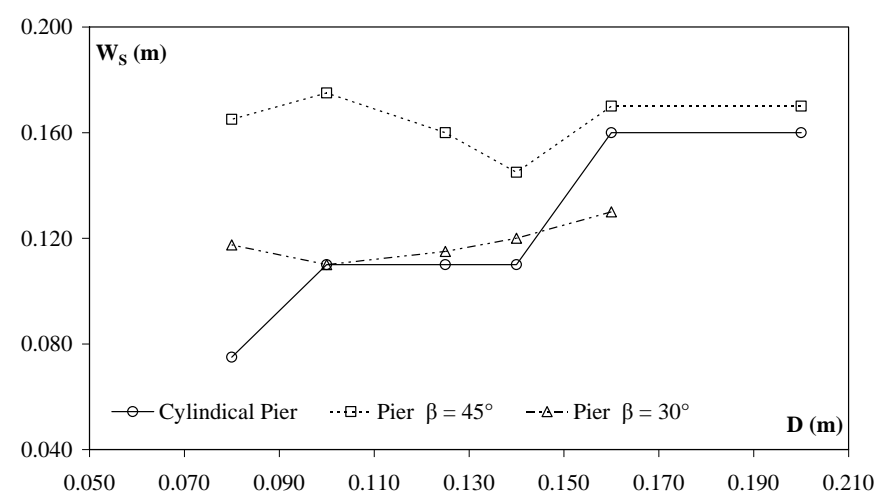

Figure 3. Front scour width Ws versus D.

As already noted, the experimental tests have been carried out in order to compare the behaviour of the various configurations (reported in Fig. 2) with respect to the expected scour phenomena around the piers, rather than achieve an absolute determination of scour entity. In this phase of research, therefore, the tests have been effected for a single value of slope, flow rate and test duration, as already mentioned, and thus in a single framework of hydrodynamic comparison.

The experimental data collected made it possible to extrapolate (at the end of each test) the scour values of the area in front of the pier and, therefore, relative to the horseshoevortex: such values are reported in Table 1 (for each diameter $\mathrm{D}$, also expresses in percentage terms, with respect to the scour values for the circular piers without truncated cone foundation).

As can be observed in Table 1, the scour depth $\mathrm{Y}_{\mathrm{S}}$ (starting from a practically common value corresponding to the smallest diameter $\mathrm{D}=0.080 \mathrm{~m}$ ) medially increases as pier diameter D increases.

Table 1. Experimental values of scour corresponding to the horseshoe-vortex.

\begin{tabular}{|c|c|c|c|c|c|}
\hline \multirow{2}{*}{$\mathrm{D}(\mathrm{m})$} & \multicolumn{3}{|c|}{$\underline{\mathrm{Ys}(\mathrm{m})}$} & \multicolumn{2}{c|}{ \% Varation } \\
\cline { 2 - 6 } & $\begin{array}{c}\text { Uniform } \\
\text { pier }\end{array}$ & $\beta=30^{\circ}$ & $\beta=45^{\circ}$ & $\beta=30^{\circ}$ & $\beta=45^{\circ}$ \\
\hline 0.080 & 0.060 & 0.062 & 0.060 & 4.34 & 0.17 \\
\hline 0.100 & 0.095 & 0.061 & 0.057 & -36.07 & -40.38 \\
\hline 0.125 & 0.107 & 0.073 & 0.058 & -32.06 & -45.95 \\
\hline 0.140 & 0.089 & 0.064 & 0.062 & -28.73 & -30.75 \\
\hline 0.160 & 0.119 & 0.086 & 0.068 & -27.79 & -42.57 \\
\hline 0.200 & 0.112 & - & 0.076 & - & -31.75 \\
\hline
\end{tabular}


Furthermore, in the tests conducted on piers with a truncated cone base (both those with $\beta=30^{\circ}$ and those with $\beta=45^{\circ}$ ), $Y_{S}$ has a lower value for equal diameters (again excluding the common value corresponding to the smallest diameter $\mathrm{D}=0.080 \mathrm{~m}$ ) than in the tests conducted on piers without the truncated cone foundation. In other words, in the experimental tests with piers on a truncated cone base, for every single dimension $\mathrm{D}$, scour values show a very significant percentage reduction. In particular, the reduction in scour is greater for the base with $\beta=45^{\circ}$. Moreover, the percentage variation follows a medially decreasing pattern as the diameter $\mathrm{D}$ increases (which can again be seen in Table 1).

Basically, the experimental tests show that, with all other conditions being equal, the truncated cone foundation has a more favourable shape coefficient. In the examined cases, by assigning the uniform circular pier with a shape coefficient equal to 1 (as suggested when using Breusers, Nicollet and Shen's equation (1) [11]) and attributing the entire reduction of the scour depth to the shape coefficient, shape coefficients would be obtained which can be estimated, for scour purposes, to be on average between 0.70 and 0.75 .

These values are extremely favourable shape coefficients that can be compared to the ones currently assigned to best configurations of river piers.

It should be remembered that (again in the use of equation (1)) considering piers with the sophisticated elliptical cross section with the major axis parallel to the direction of stream flow, a shape coefficient of almost 0.75 can be adopted. Moreover, it is also known that should the stream not run parallel to the major axis of such an elliptical pier, then scour would increase considerably according to the angle relative to approach flow direction $\alpha$, as can also be deduced from equation (1) and from the above mentioned nomograph of Laursen and Toch which makes it possible to deduce the coefficient $\left.f_{3}[4,11]\right]$. This increase in scour as the angle relative to approach flow direction varies is obviously not expected for circular piers and, therefore, for the piers with a truncated cone base used in the experimental tests presented here which are axially symmetrical. Moreover, as shown by Melville and Raudkivi [20], in case of circular piers a reduction in scour depth can be achieved if the top of the foundation is within the scour hole but below the bed surface otherwise an increase in scour depth could be verified. In a mobile bed, the foundation position with reference to the bed surface can vary with time so that the evaluation of scour depth appears to be uncertain. Such a problem seems to be less important in case of piers with truncated cone foundation whose width gradually varies with the level considered. Therefore a considerable technical advantage can be altogether expected in using truncated cone foundations like those tested which are certainly deserving of further investigation from both a quantitative and a qualitative point of view.

In order to analyse the described experimental results with a view to their application, Figure 4 reports the experimental values of the $Y_{s} / b_{p}$ and $y / b_{p}$ ratios (with $b_{p}=D$ ) so as to obtain a comparison of some empirical equations whose representation can be attributed to these dimensionless ratios.

In particular, the comparison has been made using the equation (1) proposed by Breusers, Nicollet and Shen [11] and with the more recent equation proposed by the Florida
Department of Transportation [14] in the simple case of a single pier.

The latter equation, developed substantially by Sheppard $[12,13]$ on the basis of experimental data, for the clearwater field tested here $\left(0.47<\mathrm{V} / \mathrm{V}_{\mathrm{cs}}<1\right)$, can be written as follows:

$$
\begin{aligned}
& \frac{Y_{s}}{b_{p}^{*}}=2.5 \tanh \left[\left(\frac{y}{b_{p}^{*}}\right)^{0.4}\right] \cdot\left\{1-1.75\left[\ln \left(\frac{V}{V_{c s}}\right)\right]^{2}\right\} . \\
& \cdot\left[\frac{b_{p}^{*} / d_{50}}{0.4\left(b_{p}^{*} / d_{50}\right)^{1.2}+10.6\left(b_{p}^{*} / d_{50}\right)^{-0.13}}\right]
\end{aligned}
$$

In equation (3), in addition to the already mentioned symbols, $\mathrm{b}_{\mathrm{p}}{ }^{*}$ indicates the so-called effective diameter (which in the case of cylindrical piers coincides with the pier diameter D) while for the critical velocity $\mathrm{V}_{\mathrm{cs}}$ (taking into account Shield's diagram) the following equation is suggested:

$$
V_{c s}=2.5 \cdot U_{*_{c}} \ln \left(\frac{y}{2.72 \cdot Z_{0}}\right)
$$

In equation (4) (referring the reader for brevity's sake to the Manual of the Florida Department of Transportation [14]) $\mathrm{U}_{*_{\mathrm{c}}}$ is the critical friction velocity while $\mathrm{Z}_{0}$ is a parameter calculated as a function of the critical Reynolds number $\mathrm{R}_{\mathrm{ec}}$. In actual fact, as the value of the $\mathrm{V} / \mathrm{V}_{\mathrm{cs}}$ ratio in the experimental tests carried out has been estimated to be close to 1, Fig. 4 reports for the various diameters tested (bearing in mind that greater scour occurs for values of $\mathrm{V}=\mathrm{V}_{\mathrm{cs}}$ ) the envelope of the curves deduced by equation (3) with $\mathrm{V} / \mathrm{V}_{\mathrm{cs}}=1$.

The experimental values appear to be consistent with the values predicted by equations (1) and (3) and occupy an intermediate position between the curves represented in Fig. 4.

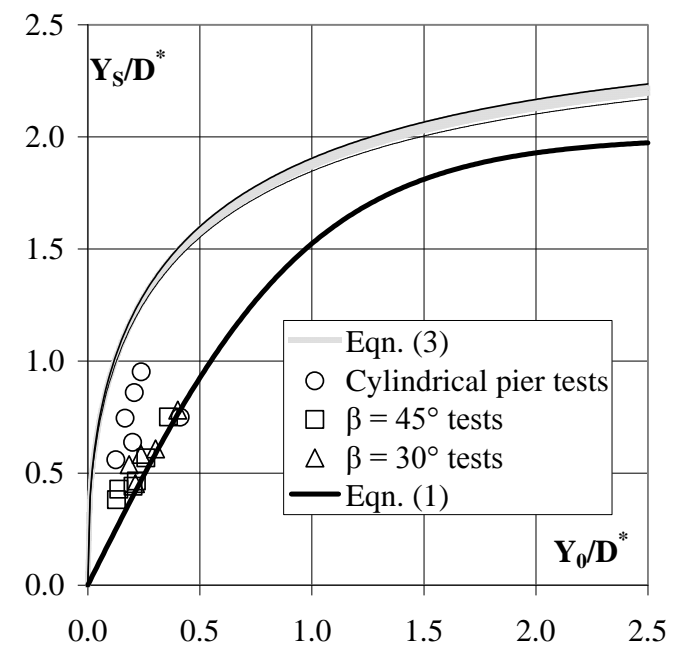

Figure 4. Comparison of the experimental values with equations (1) and (3). 
In particular, the experimental values show that scour around piers with a truncated cone base is smaller and in good agreement with equation (1) proposed by Breusers, Nicollet and Shen [11]; this equation (1) seems, however, to underestimate the experimental values obtained for piers without a truncated cone base (cylindrical).

Furthermore, all the tests show scour values that are substantially lower than the estimate made using the equation (3) proposed by the Florida Department of Transportation [14]. Therefore, for the particular geometries used in the tests, equation (3) is a significantly precautionary envelope relation for estimating scour values.

\section{Conclusions}

This study has examined circular piers which, as is well known, not only have a favourable shape coefficient but also maintain this value for any variation in stream flow direction.

In particular, the experimental tests carried out using a truncated cone as the circular pier's foundation showed a lower scour depth than that detected in experimental tests using circular piers of the same diameter but without the truncated cone foundation.

In actual fact the reduction in scour detected in the tests with the truncated cone foundation can be attributed to the modification of the complex distribution of velocity within the scour, which is characterized by components that are vertical and transverse to the flow direction, with fluid involved in vortex movements (horseshoe-vortex and wake-vortex).

The pressure field deriving from the presence of the pier results in gradients that tend to concentrate whirling thread and then release them as dissipating vortexes that essentially cause localized erosion.

On passing the pier, the wake vortexes oscillates over time towards the sides: the non-uniform distribution of velocity then gives rise to vertical components.

The truncated cone foundation spatially modifies the whirling phenomena of the horseshoe-vortex (especially the counter-vortex) which in this case partly occur on solid surfaces; moreover the truncate cone accompanies the fluid threads into the area where the horseshoe-vortexes is shed: the different pattern of the hydrodynamic phenomenon on the one hand leads to a reduction in scour depth while, on the other, it creates a limited extension in the surface subject to erosion (which assumes an almost constant width for each value of $\beta$ ).

In actual fact, the modification of vortex phenomena is evidenced by the different position for the onset of erosion. Hager and Oliveto [18] pointed out that scour occurs around the pier in an area about $70^{\circ}$ from the channel axis (coinciding with the pier axis) and then extends on the whole front section where the horseshoe-vortex is located.

In the experimental tests conducted with the truncated cone foundations it was observed that scour originates in an area close to an angle from the channel axis ranging between $80^{\circ}$ and $90^{\circ}$ for the various geometries before extending all over the pier front

The results obtained with the particular foundation shape of the studied pier (which can also be adapted to more complex foundation geometries, i.e. like the ones reported in the Manual State of Florida, see Fig. 1 [14]) show a favourable shape coefficient and suggest that the test schedule should be extended by including a larger number of diameters and varying the dynamic conditions of the stream flow, the height and bevel angle $\beta$ of the truncated cone base, and the duration of the tests.

\section{References}

[1] E.M. Laursen, "Observation on the nature of scour." Proc. 5th Hydraulic Conference, University of Iowa, Studies in Engineering, Iowa City (IA), Vol.34, pp. 179-197, 1952.

[2] H.W. Shen, V.R. Schneider and S.S. Karaki S.S., "Mechanics of local scour", Colorado State University, Civil Engineering Dept., Fort Collins, Colorado, 1966.

[3] B.W. Melville, "Local scour at bridge sites", University of Auckland, School of Engineering, Auckland, (NZ), Report n. 117, 1975.

[4] E.M. Laursen, A. Toch, "Scour around bridge piers and abutments", Iowa Highway Research Board, Ames (IA), Bull. No.4,1956.

[5] E,M. Laursen, "Scour at bridge crossings", Transactions of the American Society of Civil Engineering, Vol. 127, Part. I, n. 3294, pp 166-209, 1962

[6] E.M. Laursen, "An analysis of relief bridge scour", Journal of Hydraulics Division, ASCE, Vol.89 (3), pp 93-118, 1963.

[7] C.R. Neill, "Measurements of bridge scour and bed changes in flooding sand-bed river", Proceedings Institute of Civil Engineering, London, $n$. 30, pp 415-435, 1965.

[8] H.W, Shen, V.R. Schneider and S.S. Karaki, "Local scour around bridge piers", Journal of the Hydraulics Division, Vol.95, n. HY6, pp 19191940, 1969.

[9] S. Hanco, "Sur le calcul des affouillements locaux dans la zone des piles des ponts", Proc. $14^{\text {th }}$ IAHR Congress, Paris, Vol. 3, pp. 299-313, 1971.

[10] H.W. Shen, "Scour near piers. River Mechanics", Colorado State University, Fort Collins, Colorado, Vol.II., Chapter 23, 1971.

[11] H.N.C. Breusers, G. Nicollet and H.W. Shen, "Local scour around cylindrical piers”, J. Hydraul. Res., Vol. 15(3), pp.211-252, 1977.

[12] D.M. Sheppard, G. Zhao and B. Ontowirjo, "Local scour near single piles in steady currents", ASCE Conference Proceedings: The First International Conference on Water Resources Engineering, San Antonio, TX, 1995.

[13] D.M. Sheppard "Final Report, Scour at complex piers", Florida Department of Transportation Research Office (FDOT: BC354 RPWO 35, UF. 4910 45-04-799) State of Florida, 2003 <http://www.dot.state.fl.us>, (June 2007).

[14] .Florida Department of Transportation, "Bridge Scour Manual", State of Florida, 2005, <http://www.dot.state.fl.us>, (June 2007).

[15] L. Ciaravino, G. Ciaravino, "Preliminary experimental tests of local erosion at river piers with a particular shape", Eds. C. A. Brebbia. River Basin Management V, WIT Transactions on Ecology and the Environment, Vol. 124, pp.247-256, 2009.

[16] B.W. Melville, Y.M. Chiew, "Time scale for local scour at bridge piers", Journal of Hydraulic Engineering, Vol. 125 (1), pp 59-65, 1999.

[17] W.H. Hager, G. Oliveto, "Temporal evolution of clear-water pier and abutments scour" Journal of Hydraulic Engineering, Vol. 128(9): pp.811-820, 2002 (b).

[18] W.H. Hager, G. Oliveto, "Further results to time-dependent local scour at bridge elements", J. Hydraul. Eng., Vol. 131(2), pp. 97-105, 2005.

[19] A.J. Raudkivi, R. Ettema, "Clear-water scour at cylindrical piers", J. Hydraul. Eng., Vol. 109 (3), pp. 339-350, 1983.

[20] B.W. Melville, A.J. Raudkivi,"Effects of foundation geometry on bridge pier scour”, J. Hydraul. Eng., Vol. 122(4), pp. 203-209, 1996 